\title{
REFLEXÕES SOBRE OS SABERES DOCENTES E A PRÁTICA NOS ESTÁGIOS: POSSIBILIDADES NA FORMAÇÃO DE UM FUTURO PROFESSOR DE QUÍMICA
}

\author{
REFLECTIONS ON TEACHING KNOWLEDGE AND PRACTICE IN INTERNSHIPS: \\ POSSIBILITIES IN THE FORMATION OF A FUTURE CHEMISTRY TEACHER
}

\author{
ENIO DE LORENA STANZANI* \\ FERNANDO BASTOS** \\ MARINEZ MENEGHELLO PASSOS***
}

\section{RESUMO}

Este artigo traz resultados de uma pesquisa que objetivou investigar o percurso de um licenciando nos estágios supervisionados, buscando compreender como o processo de orientação, fundamentado nas pesquisas da área, pôde contribuir para a reelaboração de suas ideias iniciais acerca dos saberes e da prática docente. 0 percurso metodológico pautou-se na análise das entrevistas realizadas ao longo do desenvolvimento de duas disciplinas de estágio, ofertadas em um curso de Licenciatura em Química. As considerações advindas deste movimento investigativo apontam que, inicialmente, o licenciando prioriza os saberes pedagógicos, referindo-se às diferentes formas de trabalhar 0 conteúdo, porém ainda não apresenta preocupações relacionadas à integração entre os saberes docentes. No decorrer das atividades, entretanto, reelabora suas ideias, demandando atenção aos outros saberes - disciplinar, curricular, experiencial - e à articulação entre eles, a fim de contemplar um planejamento e o desenvolvimento de uma prática fundamentada e que atendesse às especificidades do ambiente escolar.

Palavras-chave: Formação Inicial de Professores de Química. Orientação de Estágio. Saberes Docentes.

\section{ABSTRACT}

This paper presents results of a study that aimed to investigate the course of a trainee teacher throughout a supervised internship, in order to understand how the mentoring process, based on some research on this topic, can contribute to the re-elaboration of their initial ideas about the teaching practice, within the theory of Teaching Knowledge. The methodological course was based on the analysis of interviews conducted during the development of two internship disciplines, offered in a degree in Chemistry. The results indicate that, initially, the trainee teacher prioritizes the pedagogical knowledge, referring to different ways of teaching the content, but still does not express concern over the integration among the teaching knowledge. However, the ideas are re-elaborated during the activities, which requires attention to other pieces of knowledge and to the articulation among them, so as to cover the lesson planning and the development of a more reasonable practice that meets the specificities of the school environment.

Keywords: Initial Teacher Education. Academic Mentorship. Teaching Knowledge.

\footnotetext{
* Doutor em Educação para a Ciência. Universidade Tecnológica Federal do Paraná - Câmpus Apucarana. eniostanzani@utfpr.edu.br. Orcid: 0000-0002-1787-0534.

** Doutor em Educação. Universidade Estadual Paulista ‘Júlio de Mesquita Filho' - Câmpus Bauru. ferbastos@fc.unesp.br. Orcid: 0000-0001-6672-0906.

*** Doutora em Educação para a Ciência. Universidade Estadual de Londrina. marinezpassos@uel.br. Orcid: 0000-0001-8856-5521.
} 


\section{INTRODUÇÃO E POSICIONAMENTO TEÓRICO}

Ao longo dos últimos anos, diversos estudos na área de Ensino de Ciências, assim como documentos oficiais do Ministério da Educação, mostraram-se preocupados com os processos formativos, visto que os resultados das pesquisas apontavam para lacunas e problemáticas a serem superadas nesse contexto. Desta forma, além de levantar e discutir esses problemas, que tornam a formação inicial de professores insuficiente frente à complexidade da profissão, essas investigações buscaram indicar caminhos e possibilidades de superação, a fim de formar professores mais preparados e comprometidos com uma educação de qualidade (FONSECA; SANTOS, 2016; CARVALHO; GIL-PÉREZ, 2011; SILVA; SCHNETZLER, 2011; MALDANER, 2006).

Uma questão muito recorrente nos estudos (TARDIF, 2014; AIRES; TOBALDINI, 2013; GAUTHIER et al., 2013; KOLLAS et al., 2013) refere-se a: como os processos formativos podem auxiliar na construção e reelaboração dos saberes docentes mobilizados na prática cotidiana? Uma vez que, ao considerar esses saberes como elementos centrais para uma formação reflexiva e crítica dos futuros professores, atribui-se novos objetivos e perspectivas à formação, rompendo "[...] profundamente com o modelo tradicional que estabelecia uma separação nítida entre os lugares de mobilização (o mundo do trabalho), de produção (o mundo da pesquisa) e de comunicação (o mundo escolar) dos saberes e das competências (TARDIF, 2014, p.288).

Entendendo, portanto, que a função do professor não se limita a transmitir conhecimentos já construídos, Tardif (2014) argumenta sobre a relevância em compreender as diferentes relações estabelecidas entre esses saberes, os quais podem ser definidos como plurais. Tais saberes constituem-se pela interação entre saberes oriundos da formação profissional - transmitidos pelas instituições de formação de professores (pedagógicos); de saberes disciplinares - correspondentes aos diversos campos do conhecimento (Química, Física, Biologia...) dispostos em nossa sociedade; curriculares - referentes aos discursos, objetivos, conteúdos e métodos a partir dos quais a instituição escolar categoriza e apresenta os saberes sociais; experienciais - relativos àqueles que brotam da experiência e são por ela validados. Assim, mais do que enfatizar conteúdos e práticas descontextualizadas, são os saberes da ação, o conhecimento dos professores em exercício e as práticas profissionais que passam a constituir o quadro de referência da formação dos professores (TARDIF, 2014; BORGES; TARDIF, 2001).

Complementando as ideias expostas anteriormente, Almeida e Biajone (2007) destacam 0 potencial dos estudos sobre os saberes dos professores no desenvolvimento de ações formativas, uma vez que essas consideram as dimensões pessoal, profissional e organizacional da profissão docente, valorizando os diferentes aspectos da história individual e profissional do professor e compreendendo-o como um profissional que adquire e desenvolve conhecimentos a partir da prática e no confronto com as condições da profissão.

Diante dessa perspectiva, esses estudos buscaram revelar e compreender como os saberes profissionais são integrados concretamente nas tarefas dos professores, e como e porque os professores os incorporam, produzem, utilizam, aplicam, validam, transformam, resignificam ou abandonam, em função dos limites, das contingências e dos recursos inerentes às atividades educativas. Sendo assim, em sua trajetória, o professor é tomado como mobilizador de saberes profissionais, uma vez que, "constrói e reconstrói seus conhecimentos, conforme a necessidade de utilização dos mesmos, suas experiências, seus percursos formativos e profissionais" (NUNES, 2001, p. 27). 
Desse modo, considerando a diversidade de saberes mobilizada pelo professor em sua prática profissional, é importante que tais saberes sejam integrados e problematizados na formação dos professores, uma vez que o processo de construção dos conhecimentos da docência tem seu início na formação inicial que, por sua vez, caracteriza-se como processo de construção da significação da profissão docente, pois representa o princípio da aprendizagem profissional, atribuindo 0 conhecimento básico ao futuro professor (TARDIF, 2014; IMBERNÓN, 2011).

Considerando tal contexto, Carvalho e Gil-Pérez (2011) afirmam sobre a relevância em evitar propostas didáticas prontas, favorecendo ações que objetivem um processo de mudança didática, que façam os futuros professores refletirem sobre suas próprias concepções e modificarem suas perspectivas a partir de processos fundamentados na cooperação entre os sujeitos envolvidos, dando ao professor 0 status de pesquisador e produtor de saberes.

Diante do exposto, neste artigo trazemos os resultados de uma pesquisa que teve por objetivo investigar o percurso de um estagiário ao longo dos estágios supervisionados de um curso de Licenciatura em Química, buscando compreender como as atividades propostas podem contribuir para que o licenciando reelabore suas ideias iniciais acerca da prática docente, incorporando as orientações dos referenciais teórico-metodológicos adotados na construção e no desenvolvimento de seus planejamentos didáticos, em uma análise à luz da teoria dos Saberes Docentes proposta por Tardif (2014).

\section{DESTAQUES METODOLÓGICOS}

A pesquisa foi desenvolvida em uma Universidade Federal localizada no interior do Estado do Paraná com seis licenciandos em Química que cursavam as disciplinas de Estágio Supervisionado 2 (ES2) e 3 (ES3), ofertadas no $6^{0}$ e $7^{0}$ períodos do curso, respectivamente. Os dados coletados são parte de um projeto mais amplo ${ }^{1}$ e, nesse sentido, optamos por, neste artigo, apresentar o percurso de apenas um dos sujeitos de pesquisa, o qual receberá o nome fictício John².

0 Quadro 1 a seguir traz a descrição das atividades formativas e de pesquisa vivenciadas por John. Tais esclarecimentos buscam elucidar algumas das informações e interpretações postas na continuidade.

Quadro 1 - Síntese das atividades formativas e de pesquisa.

\begin{tabular}{|c|l|}
\hline Atividades desenvolvidas & \multicolumn{1}{c|}{ Descrição } \\
\hline \multicolumn{2}{|c|}{ Estágio Supervisionado 2 (ES2) } \\
\hline Entrevista Inicial (ES2) & $\begin{array}{l}\text { Teve como objetivo identificar concepções, sentimentos e atitudes a respeito das relações entre planejamento } \\
\text { e ação docentes e da relevância das pesquisas da área de Ensino de Ciências nesse processo. A intenção foi } \\
\text { compreender como o futuro professor, em um primeiro momento, interpretava a realidade, seus conheci- } \\
\text { mentos e experiências. }\end{array}$ \\
\hline Aula 1 & $\begin{array}{l}\text { A partir do conteúdo químico 'Modelos Atômicos', o qual foi definido por sorteio, o licenciando, sem orienta- } \\
\text { ção, elaborou uma aula de 50 minutos e apresentou-a aos outros licenciandos. }\end{array}$ \\
\hline
\end{tabular}

\footnotetext{
1 Dado o recorte aqui apresentado, a pesquisa caracteriza-se como um Estudo de Caso, pois tem um campo de trabalho específico: é o estudo de um caso, sendo este bem delimitado e de contornos claramente definidos. 0 caso se destaca por se constituir numa unidade dentro de um sistema mais amplo (LÜDKE; ANDRÉ, 2013).

20 nome fictício "John" foi adotado com 0 objetivo de manter 0 anonimato do licenciando e, também, fazer alusão a um dos cientistas que foram importantes para o desenvolvimento das teorias científicas trabalhadas no decorrer dos estágios, no caso, John Dalton e suas contribuições à teoria atômica.
} 


\begin{tabular}{|c|c|}
\hline Reunião de Orientação & $\begin{array}{l}\text { De posse do vídeo da Aula 1, pesquisador/professor e licenciando realizaram a análise e reflexão dos principais } \\
\text { pontos da aula e, na sequência, foram discutidos os referenciais teóricos que deveriam fundamentar a Aula 2: } \\
\text { Situação de Estudo (SE) e abordagem histórica dos conceitos. }\end{array}$ \\
\hline $\begin{array}{c}\text { Estudo de Referenciais } \\
\text { Teóricos }\end{array}$ & $\begin{array}{l}\text { Foram propostas atividades e discussões de textos relacionadas à SE e à abordagem histórica dos conceitos } \\
\text { químicos na Educação Básica. Destacamos que, nesse momento, o trabalho com a SE teve como objetivo } \\
\text { problematizar questões relacionadas ao planejamento e às etapas da aula, visto que a SE, de acordo com os } \\
\text { referenciais que a norteiam, deve contemplar um planejamento mais amplo. }\end{array}$ \\
\hline Aula 2 & $\begin{array}{l}\text { A partir do mesmo conteúdo abordado na aula anterior - 'Modelos Atômicos' - o licenciando preparou uma } \\
\text { nova aula ( } 50 \text { minutos), porém agora contemplando os pressupostos da dinâmica pedagógica SE e os aspec- } \\
\text { tos históricos do conceito abordado, a qual também foi apresentada aos demais estudantes da turma. }\end{array}$ \\
\hline Entrevista Final (ES2) & $\begin{array}{l}\text { Teve como propósito refletir sobre o processo de estágio, principalmente aos aspectos positivos e negativos } \\
\text { relacionados à elaboração e ao desenvolvimento das aulas. }\end{array}$ \\
\hline \multicolumn{2}{|r|}{ Estágio Supervisionado 3 (ES3) } \\
\hline $\begin{array}{l}\text { Planejamento e } \\
\text { execução da sequência } \\
\text { didática nas escolas }\end{array}$ & $\begin{array}{l}\text { A partir do conteúdo 'Cinética Química', John elaborou, com a orientação do pesquisador/professor, uma SE } \\
\text { de } 04 \text { aulas utilizando as mesmas indicações propostas para a Aula 2. Essas quatro aulas foram ministradas } \\
\text { aos alunos do } 2^{\circ} \text { ano do Ensino Médio de uma escola estadual do Estado do Paraná. }\end{array}$ \\
\hline Entrevista Final (ES3) & $\begin{array}{l}\text { Buscou-se refletir sobre os aspectos relacionados ao planejamento das aulas; à inserção das abordagens } \\
\text { históricas no ensino dos conceitos científicos; ao uso da proposta de ensino SE; e, ao papel das atividades } \\
\text { vivenciadas ao longo dos estágios na formação do futuro professor. }\end{array}$ \\
\hline
\end{tabular}

Fonte: Os autores.

Nos estágios, John elaborou suas propostas de aula a partir dos conteúdos 'Modelos Atômicos' (ES2) e 'Cinética Química' (ES3). No ES2, a primeira aula contemplou o modelo atômico de Bohr e, dentre as atividades propostas, destaca-se o uso da experimentação e da História da Ciência. No segundo momento, o licenciando optou por trabalhar com o modelo atômico de Dalton e, desta vez, deu ainda mais destaque à discussão histórica, utilizando como problematização uma dinâmica sobre a construção dos modelos na Ciência, dentro das orientações proposta para a SE', a qual recebeu 0 título 'A evolução dos modelos na Ciência'.

No semestre seguinte, em sua primeira experiência no ambiente escolar enquanto professor, iniciando 0 segundo momento da pesquisa (ES3), John, devido à sua carga horária de trabalho, optou por fazer o estágio no período noturno, em um colégio estadual no mesmo município da Universidade Federal que cursava. 0 conteúdo indicado pelo professor regente (da turma em que estagiou) foi 'Cinética Química', ministrado para os estudantes do segundo ano do Ensino Médio, sendo disponibilizadas quatro aulas de 50 minutos para o desenvolvimento das atividades. A partir de então, John, com auxílio do pesquisador/professor, iniciou o processo de elaboração das aulas que integraram a SE intitulada 'Os benefícios da maçã̃. A leitura de textos, principalmente relacionados à abordagem histórica, e as atividades práticas foram as principais estratégias utilizadas pelo licenciando em sua proposta.

A fim de atingir o objetivo da presente investigação, foram analisados somente os dados provenientes das entrevistas realizadas com o licenciando - destacados no quadro anterior (Quadro 1). Dado 0 recorte analítico, o procedimento de análise e de interpretação fundamentou-se nos pressupostos da Análise de Conteúdo (AC), proposta por Bardin (2011) e Moraes (1999). De acordo com os autores, a AC constitui uma metodologia de pesquisa utilizada na descrição e interpretação do

3 A Situação de Estudo, originalmente proposta por Maldaner et al. (2001), é pensada enquanto uma ferramenta para organização curricular, compreendendo práticas interdisciplinares. Porém, assim como nos trabalhos desenvolvidos por Stanzani et al. (2016) e Massena (2015), as SE serão utilizadas em nosso contexto de forma disciplinar, ou seja, dentro de uma mesma disciplina, entretanto serão "elaboradas buscando-se dar a elas um formato diferenciado do que se vê normalmente em uma aula expositiva" (MASSENA, 2015, p. 48).

4 Os resultados da SE 'Os benefícios da maçã' foram publicados em GATTO, M. A.; STANZANI, E. L.; GREGORIO, A. P. H. Situação de Estudo no Ensino de Cinética Química: possibilidades a partir de uma abordagem histórica. EXPERIÊNCIAS EM ENSINO DE CIÊNCIAS (UFRGS), v. 14, p. 160-176, 2019. 
conteúdo de toda classe de documentos e textos. Desse modo, conduzindo a descrições sistemáticas, qualitativas ou quantitativas, auxilia na reinterpretação das mensagens, permitindo uma compreensão de seus significados em um nível que vai além de uma leitura comum.

Inicialmente fizemos uma leitura flutuante dos dados coletados em todas as entrevistas realizadas e, a partir disso, elaboramos textos sobre as respostas do licenciando, os quais auxiliaram na estruturação das Unidades de Análise (UA). Após tal processo, agrupamos as UA, segundo as categorias previamente estabelecidas, e os textos de fundamentação deste movimento analítico metatextos - foram construídos/adaptados (Quadro 2).

Sobre o processo de categorização, Bardin (2011) divide-o em duas etapas: "o inventário: isolar os elementos; e a classificação: repartir os elementos e, portanto, procurar ou impor uma certa organização às mensagens" (p. 112). Nessa perspectiva, Moraes (1999) destaca que a análise do material precisa ocorrer de forma cíclica e circular, desse modo, "o retorno periódico aos dados, 0 refinamento progressivo das categorias, dentro da procura de significados cada vez melhor explicitados, constituem um processo nunca inteiramente concluído, em que a cada ciclo podem atingir-se novas camadas de compreensão" (p. 19). Sendo assim, apresentamos, na sequência, algumas considerações acerca desse movimento, no qual assumimos como categorias a priori a tipologia dos Saberes Docentes - Disciplinar; Pedagógico; Curricular; e, Experiencial - proposta por Tardif (2014).

Quadro 2 - Categorias e descrições adaptadas a partir da análise dos dados.

\begin{tabular}{|c|l|}
\hline $\begin{array}{c}\text { 1. Saber } \\
\text { Disciplinar }\end{array}$ & $\begin{array}{l}\text { Refere-se aos saberes correspondentes aos diversos campos do conhecimento sob a forma de disciplina - são } \\
\text { saberes sociais definidos e selecionados pela instituição universitária e incorporados na prática docente (TARDIF, } \\
\text { 2014). Em nosso contexto de investigação, esses saberes incluíram tanto o conteúdo químico, como os conceitos } \\
\text { relacionados à disciplina de História da Ciência/Química. }\end{array}$ \\
\hline 2. Saber & $\begin{array}{l}\text { Mesmo fazendo uma diferenciação entre saberes da formação profissional e saberes pedagógicos, "[...] frequente- } \\
\text { mente, é até mesmo bastante difícil distingui-los" (TARDIF, 2014, p. 37). Optamos por intitular essa categoria de 'saber } \\
\text { Pedagógico } \\
\text { de ensino, as quais se pautaram nessas teorias, orientando diversas abordagens e estratégias utilizadas pelos profes- } \\
\text { sores em sua prática profissional. Como exemplos, destacamos: as Situações de Estudo e a abordagem histórica. }\end{array}$ \\
\hline $\begin{array}{c}\text { 3. Saber } \\
\text { Curricular }\end{array}$ & $\begin{array}{l}\text { São conhecimentos relacionados à forma como as instituições educacionais fazem a gestão dos conhecimentos } \\
\text { socialmente produzidos e que precisam ser transmitidos aos estudantes (saberes disciplinares). Apresentam-se, } \\
\text { concretamente, sob a forma de programas escolares, e estão relacionados ao conjunto de conteúdos, à articulação } \\
\text { entre eles e aos objetivos do seu ensino (TARDIF, 2014). Esses foram pouco enfatizados por John nas entrevistas, } \\
\text { limitando-se, principalmente, a reflexões sobre o planejamento das aulas e à maneira como as atividades são } \\
\text { organizadas e se conectam no contexto em que as regências foram desenvolvidas. }\end{array}$ \\
\hline $\begin{array}{c}\text { 4. Saber } \\
\text { Experiencial }\end{array}$ & $\begin{array}{l}\text { Segundo Tardif (2014), os saberes experienciais relacionam-se aos saberes construídos ao longo das experiências } \\
\text { do professor em seu local de trabalho. Em nosso contexto de investigação, dado que o licenciando estava em } \\
\text { formação inicial, os saberes experienciais considerados englobaram não apenas o contato com o ambiente escolar } \\
\text { - seja por meio do estágio de observação ou projetos de ensino - mas também os saberes provenientes da formação } \\
\text { escolar anterior, assim como os pessoais, que o influenciavam e faziam-no refletir sobre suas escolhas relaciona- } \\
\text { das à profissão docente. }\end{array}$ \\
\hline
\end{tabular}

Fonte: Os autores.

Apresentado, portanto, o contexto e os caminhos metodológicos referentes à pesquisa em discussão, na seção seguinte descreve-se o processo interpretativo, que teve como intenção analisar o percurso do licenciando no decorrer dos estágios, com base nos objetivos supracitados. 


\section{RESULTADOS E DISCUSSÕES}

A fim de organizar o procedimento de análise e de interpretação dos dados, optamos por dividir tal processo de acordo com as atividades (entrevistas) mencionadas e destacadas no Quadro 1.

\section{ANÁLISE DA ENTREVISTA INICIAL (ES2)}

Antes de começar o desenvolvimento das atividades relacionadas à pesquisa, o licenciando foi entrevistado pelo pesquisador/professor, conforme consta nos procedimentos metodológicos. Neste tópico, assim como nas análises posteriores, o processo interpretativo seguiu a sequência em que as questões foram realizadas, desse modo, as falas de John não foram inseridas em sua completude ${ }^{5}$, trouxemos somente alguns exemplos de depoimentos, em nossas argumentações, em função da quantidade excessiva de informações coletadas. Cabe enfatizar que nosso intuito foi o de compreender como os saberes docentes eram mobilizados pelo licenciando ao longo das atividades planejadas para os estágios.

Na primeira questão - Você pensa em ser professor? -, o licenciando descreveu experiências pessoais que 0 levaram a optar pela carreira docente. Relatou sobre 0 papel de professores que 0 influenciaram, como também da própria família que, por ter origem humilde, sempre o incentivou a estudar e a ser professor, evidenciando uma forte influência familiar/social na consolidação de sua escolha profissional: "A gente era muito humilde e meu pai não teve estudo, nada, e sempre falava para eu estudar $(E-1)^{6}[\ldots]$ até porque minha mãe era professora" (E-2).

Além disso, em meio às suas considerações, John fez uma diferenciação, a partir de experiências anteriores, da maneira como sua professora de Química desenvolvia a proposta de ensino para os conteúdos, fato esse que despertou sua atenção e influenciou-o a cursar Química. Percebe-se, em suas colocações, tanto a presença de fatores emocionais e motivacionais, baseados em saberes construídos a partir da experiência enquanto aluno da Educação Básica, como também em ponderações a respeito de aspectos pedagógicos, os quais tornaram a professora de Química, citada por ele, diferente dos demais professores: "Ela passava a Química de um jeito tão fácil, que eu pensava, nossa, que legal, um dia quero ser igual a essa professora, fez a diferença" (P-1).

John, ao trazer suas experiências de vida nos relatos, ratificou a relevância dada aos saberes pessoais e da formação escolar anterior, os quais são reelaborados a partir de uma bagagem de vivências em ambientes diversos, que demandaram a mobilização de diferentes conhecimentos e comportamentos, dados os papéis que o sujeito pode assumir em cada um desses espaços. Desse modo, 0 licenciando corroborou com as reflexões de Tardif (2014), pois, segundo ele, a construção dos saberes docentes está longe de ser um processo individual e atribuído a apenas um contexto de formação.

Com relação à segunda questão, nossa proposta era a de levantar as ideias iniciais do licenciando sobre quais seriam os saberes necessários para que o professor desenvolvesse sua prática em seu contexto profissional. Considerando a não experiência de John no ambiente escolar, quais seriam os principais elementos destacados por ele ao pensar no planejamento e na ação do professor em sala de aula?

5 Os dados em sua totalidade e outras informações sobre esta pesquisa, podem ser acessados em Stanzani (2018).

60 s fragmentos representativos receberam códigos de acordo com a sequência de falas do licenciando alocadas nas categorias (assumidas a priori) dos Saberes Docentes. Por exemplo, ao longo de toda a entrevista inicial foram classificados 13 fragmentos na categoria Saber Experiencial dentre as cinco questões propostas, assim os fragmentos receberam os códigos E-1 a E-13. Para as outras categorias foi adotada a mesma lógica: D (disciplinar), P (pedagógico) e C (curricular), seguido do número correspondente ao fragmento analisado. 
Ao responder a essa questão, John relatou, inicialmente, a respeito do saber disciplinar - "Além do conteúdo?" (D-1). Ao analisar o contexto e a resposta dada, percebe-se que John dava aos saberes disciplinares um status primeiro, ou seja, o principal para que o professor conseguisse desenvolver sua prática era saber o conteúdo a ser ensinado. De fato, esse é um elemento muito relevante para o trabalho do professor, um professor de Química precisa, necessariamente, conhecer os conteúdos estruturantes da disciplina, porém dois aspectos nos chamaram a atenção.

Primeiramente, ao considerar o saber disciplinar como prevalecente, o licenciando demandou pouca preocupação à articulação entre os diferentes saberes. Sua abordagem assumiu uma ênfase "conteudista", correspondendo a um modelo de ensino muito criticado pelas pesquisas da área (CARVALHO; GIL-PÉREZ, 2011; SILVA; SCHNETZLER, 2011). 0 segundo aspecto diz respeito a esta ter sido a única menção aos saberes disciplinares no decorrer de toda a entrevista, o que nos causou certa preocupação, pois para John ensinar era algo fácil, bastando apenas agregar algumas ferramentas e técnicas, que teriam como objetivo auxiliar na transmissão dos conceitos.

Ainda pensando sobre os saberes necessários para que o professor desenvolvesse sua prática, John argumentou sobre o papel fundamental de uma "boa formação" na consolidação dos saberes dos professores, que, por conseguinte, teriam influência direta no desempenho em sala de aula. Na sequência, ainda dando destaque aos saberes pedagógicos, comentou sobre como a formação possibilita que os licenciandos tenham contato com diferentes metodologias de ensino e reforçou a necessidade de possuírem saberes atrelados a outras áreas do conhecimento, como à Psicologia da Educação.

0 professor, ele tem que ter uma boa formação para conseguir dar aula (P-2). [...] Por exemplo, essa coisa de atividade experimental, fazer uma aula dinâmica para ver se 0 aluno tem mais facilidade em aprender, a gente tá tendo isso agora ( $\mathrm{P}-4)$. [...] ter uma capacitação na área de Psicologia da Educação, para entender melhor 0 ambiente (P-5).

Nas menções aos saberes pedagógicos, John mostrou certo conhecimento acerca de estratégias e recursos, os quais poderiam auxiliar no planejamento e na condução das atividades pelo professor, enfatizando, principalmente, o papel da formação nesse contexto. Porém, em nenhum momento o licenciando buscou articular essas ideias, a fim de construir um arcabouço teórico e metodológico que possibilitaria a condução de uma prática reflexiva frente a incertezas e à complexidade da profissão. Assim, o licenciando deu destaque a aspectos importantes, que deveriam ser levados em conta pelo docente, como 0 uso da experimentação. No entanto, não aprofundou em suas colocações essa questão, relacionando-a ao como fazer, dando, portanto, a ideia de algo muito mais prescritivo do que aplicável à realidade da sala de aula.

Finalizando suas considerações para tal questão, o licenciando comentou sobre a necessidade de a formação preparar o professor para o contexto real de trabalho, atribuindo aos saberes da experiência certa importância na construção e na consolidação dos saberes profissionais.

0 que temos que ver é que estamos sendo formados para atuar em um ambiente que a gente não está esperando, um ambiente complexo (E-5). Tenho uma prima que é professora, ela comenta que trabalha de acordo com a sala. Se a turma é boa ela dá atividades diferenciadas, ela negocia isso com a turma, usa como troca mesmo. Foi a maneira que ela conseguiu de dominar a sala, é a experiência, né (E-6)? 
Além de destacar os saberes experienciais, outro ponto que nos chamou a atenção nesse trecho do depoimento de John está relacionado à questão do "choque de realidade" e de como a relação entre os saberes docentes e esse primeiro contato com o ambiente profissional pode ser decisivo na estruturação e manutenção dos saberes mobilizados pelo futuro professor.

Assim, esse processo de reflexão constante sobre a prática e também sobre outros aspectos relacionados à profissão docente tem como objetivo propiciar ao licenciando um espaço de formação que considere todas essas orientações, buscando, principalmente, evitar que as teorias discutidas e incorporadas ao longo do processo formativo sejam abandonadas durante os anos iniciais de trabalho, uma vez que há uma tendência em desvalorizar a formação profissional anterior frente aos desafios inerentes à prática profissional (TARDIF, 2014; TARDIF; LESSARD; LAHAYE, 1991).

Ao abordar a terceira questão - Você acha que as disciplinas específicas da Licenciatura possibilitam que todos esses saberes sejam construídos? - John afirmou que as disciplinas específicas da Licenciatura poderiam contemplar todos os saberes necessários ao trabalho do professor, fundamentando seus argumentos nas experiências anteriores, porém destacou a insuficiência dos estágios curriculares frente à complexidade do ambiente escolar. Na sequência trazemos um depoimento em que ele faz uma analogia à formação do médico, refletindo sobre a importância da experiência na formação, a fim de preparar melhor o professor para o exercício de seu trabalho.

Não é suficiente [referindo-se ao estágio curricular], com o estagiário os alunos se comportam de outra maneira (E-9). [...] 0 médico mesmo tem um tempo muito maior de experiência, de estudo para se tornar um profissional adequado, e por que o professor não tem? Porque no estágio, às vezes a gente fica lá na escola 1, 2 meses, prepara as aulas, observa, mas, e o resto (E-10)? Então, o que a gente conclui? Que 0 professor só vai ser professor quando ele sair da universidade (E-11) e às vezes 0 choque de realidade pode mudar a maneira dele pensar (E-12).

John ressaltou uma limitação dos estágios curriculares, pois em muitas universidades brasileiras esses são os únicos momentos em que o futuro professor estabelece um contato mais significativo com 0 ambiente escolar, já desenvolvendo algumas tarefas próprias dos professores. Assim, o licenciando argumentou sobre a necessidade de um contato mais amplo, tanto relativo ao âmbito temporal, como a aspectos de qualidade dessa interação entre universidade e escola, o que, segundo ele, poderia modificar a maneira como o futuro professor percebe e age frente às situações cotidianas relativas ao trabalho docente.

Outro exemplo da dicotomia existente entre os saberes docentes apareceu na resposta do licenciando ao pensar sobre os elementos necessários para o planejamento das aulas, quando assim interpelado: Pensando no planejamento de uma aula, quais elementos você levaria em conta nessa elaboração? Na construção de seus argumentos, John citou apenas os saberes pedagógicos como essenciais para que o professor pudesse elaborar e construir seus planos de ação, evidenciando certo desconhecimento sobre os outros saberes e acerca da importante integração entre eles.

Como é que eu vou preparar 0 conteúdo (P-6)? Como inserir o conteúdo para 0 aluno (P-7)? Qual vai ser a forma de trabalhar (P-8)? A gente já teve uma capacitação para saber como trabalhar com 0 aluno $(\mathrm{P}-9)$. [...] em metodologia a gente vê várias formas de trabalhar, inserir um estudo de caso, algo que instigue 0 aluno (P-10). 
Mesmo demonstrando uma aparente inquietação com a aprendizagem, é preocupante que noções sobre o currículo e o conteúdo não apareçam nos argumentos de John, quando ele refletiu sobre os principais elementos dentro de uma proposta de aula.

Tal aspecto pode estar relacionado, provavelmente, a uma formação educacional e profissional marcada pela compartimentalização de conceitos e saberes que, especificamente no caso da formação em nível superior, dificulta que o licenciando compreenda o trabalho do professor enquanto um contexto de aplicação e reflexão sobre teorias e vivências, as quais, quando confrontadas na prática, podem ser utilizadas como fonte de conhecimento e produção de pesquisas e saberes profissionais.

Finalizando a entrevista inicial, John foi convidado a explanar sobre como a pesquisa, especificamente, aquela voltada ao ensino de Química, poderia auxiliar o professor no exercício de sua profissão.

Tem muita coisa boa para a gente pesquisar quando for preparar uma aula para 0 Ensino Médio (C-1), a Química Nova na Escola tem muito artigo legal de pesquisa, sugestão de experimento (P-13). Muitas vezes a gente tem preguiça de pesquisar, porque querendo ou não dá trabalho (E-13), planejar uma aula dá trabalho (C-2).

0 licenciando reconheceu que a produção de pesquisas na área pode ser uma aliada do professor ao elaborar e desenvolver suas aulas e atribuiu ao "comodismo" a não incorporação desses resultados ao processo de ensino e de aprendizagem, o qual precisa ter como objetivo a aprendizagem do aluno. Esse assinalamento é muito discutido por pesquisadores da área, os quais buscam apontar os motivos pelos quais há esse distanciamento entre os resultados das pesquisas e a prática do professor.

Não se limitando à questão do comodismo, tais investigações destacam que, por não integrar os professores ao processo de pesquisa, entendendo-os como produtores de saberes e, por conseguinte, sujeitos capacitados a desenvolver investigações sobre e no seu ambiente de trabalho, os próprios professores não reconhecem esses resultados e acabam reforçando a barreira existente entre 0 universo acadêmico e a sala de aula (TARDIF, 2014).

Ao responder à última questão, John trouxe suas primeiras considerações sobre a importância do planejamento para o desenvolvimento da prática, porém ainda de maneira muito pontual. Assim, entendemos que conhecer o currículo, suas orientações e até mesmo suas limitações, pareceu não ser relevante para que o futuro professor desenvolva sua prática em sala de aula.

Esse aspecto caracteriza-se como um problema mais amplo relacionado ao papel do professor em seu ambiente de trabalho - a escola. Ao não pensar no professor enquanto um ator que participa e discute sobre a construção do currículo, buscando compreender e propor melhorias aos processos de ensino e de aprendizagem na Educação Básica evidencia-se, então, certo desconhecimento do licenciando sobre esse aspecto importante do funcionamento do contexto escolar. Tal fato expõe uma lacuna presente na formação do professor, a insuficiente discussão crítica de políticas públicas voltadas à Educação (MELO, 1999).

\section{ANÁLISE DA ENTREVISTA FINAL (ES2)}

Durante a componente curricular ES2, o licenciando deveria preparar duas aulas de 50 minutos a serem ministradas aos outros licenciandos matriculados na referida disciplina, tendo como base 0 conteúdo 'Modelos Atômicos', que foi definido por meio de um sorteio. 
Desse modo, após todo o processo formativo desenvolvido na referida disciplina, o licenciando foi novamente entrevistado, agora sobre como o desenvolvimento das aulas, articulado aos momentos de discussão e reflexão fundamentados na própria prática e nos referenciais teóricos da área, possibilitaram a reelaboração e a mobilização dos saberes docentes.

Nesta entrevista ao final do ES2, embora os saberes pedagógicos ainda fossem os mais destacados pelo futuro professor, todos os outros saberes - disciplinares, curriculares e experienciais foram mobilizados durante suas considerações acerca do processo transcorrido no ES2, conforme veremos nas análises que seguem.

A questão inicial teve como objetivo possibilitar uma reflexão sobre a primeira aula ministrada por John, destacando pontos positivos e negativos tanto no processo de planejamento quanto na ação propriamente dita.

Em sua resposta, o primeiro ponto enfatizado pelo licenciando referiu-se ao saber disciplinar. Segundo John: "O principal problema que eu vi foi com relação a levar conceitos que eu não tenho domínio, acabei me atrapalhando um pouco" (D-1). Durante a execução da aula, um dos alunos questionou o futuro professor acerca do conceito íon, porém, nesse momento, John apresentou grande dificuldade em explicar o conceito a fim de sanar a dúvida do aluno.

Em alusão à primeira entrevista, vemos que John não dava muita importância ao saber disciplinar, caracterizando-o como um saber já construído e estável, o qual deveria apenas ser aplicado a situações de sala de aula, porém ao se deparar com uma questão relativamente simples, sobre um conceito que estaria diretamente relacionado ao conteúdo em discussão na aula, o licenciando pareceu se dar conta da importância de pensar não apenas em como desenvolver a aula, ou em quais ferramentas e estratégias utilizar. Agora, mesmo que em um ambiente simulado, a necessidade de um aprofundamento teórico relacionado aos conceitos químicos tornou-se um ponto central para 0 futuro professor no desenvolvimento da aula, conforme ele afirmou: "Na verdade, na hora me deu um branco, mas é um aprendizado, né?" (D-2).

Na sequência, John destacou outras problemáticas relacionadas aos saberes pedagógicos e curriculares e, nesse movimento, trouxe algumas reflexões construídas a partir de seu aprendizado no papel de estudante/licenciando. No que concerne ao currículo, o licenciando relatou sobre não conseguir concluir todas as atividades planejadas para a aula e, assim, comentou sobre uma incoerência referente à sequência inicialmente traçada: "Outra coisa que eu percebi foi que eu não fechei a aula" (C-1).

Nesse contexto, John reforçou essa ideia ao afirmar que um dos motivos da "quebra" na sequência da aula deveu-se ao fato de não ter instigado os alunos a participarem ativamente, enfatizando sobre a maneira como propôs a atividade experimental: "[...] e eu poderia ter trabalhado mais as respostas dos alunos (P-1) e no experimento poderia ter instigado mais os alunos a participarem, explicando o porquê de cada coisa" (P-2). Continuando seu raciocínio, complementou: "Eu acho que até deixei tempo para 0 aluno responder, mas eu via que ele não respondia e já ia e entregava a resposta (P-3), não questionei para levá-lo a chegar na resposta" (P-4).

Diante das falas apresentadas, alguns pontos merecem destaque. A princípio, pensar a estrutura da aula, considerando etapas que se articulem e possibilitem uma coerência - começo, meio e fim - não foi um aspecto considerado por John previamente à sua primeira experiência. Embora 0 licenciando, desde seus primeiros relatos, já mencionasse 0 uso de ferramentas e estratégias, a fim de possibilitar novas abordagens de ensino, ao se deparar com uma situação que exigiu um movimento de integração entre esses recursos e os conceitos a serem ensinados, o futuro professor indicou outras inquietações pertinentes ao trabalho do professor. Entre elas, as questões relacionadas 
à condução das atividades, buscando não só atender aos aspectos organizacionais e estruturais (saberes curriculares), mas também possibilitando que os alunos participassem da construção e ressignificação dos conceitos.

E, ainda sobre esse cenário, John trouxe algumas considerações, a fim de justificar seu posicionamento frente aos problemas relatados:

A gente tem muito professor que não espera a gente responder, principalmente aqui [referindo-se à Universidade] (E-1). A gente tem que mudar essa imagem, é uma coisa a ser mudada (E-2), mas é dif́́cil ver 0 aluno participando da resposta pelo medo de me perguntar algo que me deixa sem jeito (E-3).

Vemos, frente ao depoimento citado, como o modelo de formação pode influenciar a maneira como o futuro professor encara a realidade e busca resolver os problemas a ela relacionados, principalmente, no início de sua carreira docente. Ao discorrer sobre essa questão, o licenciando corroborou pontos muito discutidos na literatura da área, os quais salientam tópicos pertinentes à formação anterior e à ação dos professores iniciantes frente a impasses presentes nesse ambiente de múltiplas e complexas interações - a sala de aula.

A questão seguinte buscou levantar os elementos que o licenciando considerou para o planejamento da aula inicial. Percebemos aqui, novamente, que 0 saber disciplinar realmente não fez parte das preocupações de John, pois, nesse momento, enfatizou apenas as questões metodológicas.

Eu pensei no conteúdo que seria mais fácil (D-3) e que eu conseguiria aplicar um experimento bem legal (P-5). 0 que chamou atenção na verdade foi 0 conteúdo que eu pudesse explicar a partir da aula prática (P-6). Então eu encontrei 0 artigo que trazia a proposta de um experimento para trabalhar o modelo de Bohr e decidi abordar esse conceito (P-7).

Nos fragmentos anteriores, John afirmou que a escolha por trabalhar o modelo atômico de Bohr deu-se a partir da pesquisa por um experimento, que orientou o planejamento da aula. Porém, mesmo dando mais atenção a essa atividade, relatou a respeito das dificuldades inerentes à condução da proposta, a fim de promover uma participação mais ativa dos alunos.

Mesmo dando ênfase aos recursos e estratégias utilizadas na elaboração de seu planejamento, o licenciando, ainda assim, afirmou que 0 enfoque da aula foi o conteúdo: "Eu priorizava que eles entendessem 0 que eu estava ensinando, que eles entendessem os conceitos inseridos" (D-4), e complementou: "[...] mas eu não fiz com que os alunos pensassem (P-9), às vezes por eles não pensarem sobre, esse conhecimento não é adquirido da melhor maneira, né?" (P-10).

A esse respeito, ao refletirmos sobre a maneira como o licenciando lidou com os saberes disciplinares desde a entrevista inicial até o momento em que teceu considerações sobre sua primeira aula, percebemos seu movimento no sentido de compreender a relevante e necessária articulação entre os saberes, a fim de que os conceitos se tornassem inteligíveis para os alunos da Educação Básica, possibilitando que esses participassem da construção do conhecimento em um ambiente que promovesse a participação e a criticidade.

A próxima questão, centrou-se no desenvolvimento da segunda aula. Assim, questionou-se 0 licenciando sobre o processo de elaboração, considerando as orientações do pesquisador/professor. 
[...] eu vi que utilizando a história da ciência e a situação de estudo, o professor tem que ralar um pouco mais pra planejar essa aula porque essa aula tem que ser pensada (C-2). [...] às vezes essa é uma das dificuldades... que às vezes o professor não está habituado a planejar, né (E-4)?

No fragmento exposto anteriormente, John enfatizou sobre a exigência de um planejamento e de um trabalho mais enfático do professor, a fim de atender as orientações das pesquisas, visando contemplar as etapas da SE e, ao mesmo tempo, inserir a abordagem histórica dentro dessa dinâmica. Nesse contexto, corroboram as considerações de Frison (2012), visto que "[...] a ideia de que uma prática formativa, que envolva os licenciandos em processos de reconstrução curricular, como é 0 caso da produção de SEs, aumenta as chances de os licenciandos produzirem e se apropriarem dos saberes docentes necessários para ensinar" (p. 109).

Dando continuidade, destacou, a partir de experiências anteriores, que os professores não estavam acostumados a planejar, sendo esse um dos motivos para a não incorporação das recomendações dos referenciais teórico-metodológicos na prática, porém não aprofundou suas considerações a respeito.

Com relação à aprendizagem dos conceitos em articulação com 0 uso da abordagem histórica, John comentou: "[...] muitos conceitos, se a gente entender a fundo a história fica mais fácil (P-11). Então achei uma coisa legal e uma coisa que atrai a curiosidade dos alunos, né? Utilizar a história" (P-12). Mesmo não apresentando argumentos que sustentassem com maior embasamento teórico suas afirmações, foi possível inferir que John buscava contemplar alguns objetivos importantes quando pensamos na articulação entre História da Ciência e ensino de Ciências.

Finalizando essa etapa, John fez algumas ponderações acerca do desenvolvimento das duas aulas, destacando o papel das metodologias e das estratégias utilizadas.

Olhando para minha aula, eu acho que se eu tivesse aplicado a metodologia da segunda na primeira aula, aplicando a situação de estudo e história da ciência, ela ficaria muito melhor (P-14). [...] eu acho que se eu pegasse o tema da primeira, os conceitos e a experiência, e aplicasse 0 que estava sendo proposto, a aula ia ficar muito massa (P-15).

Com relação à utilização da SE na segunda aula, foi possível concluir, a partir de seu relato, que a organização e o planejamento das atividades ocorreram de forma mais dinâmica, possibilitando melhor abordagem quanto ao ensino dos conceitos e à aprendizagem, visto que, segundo John a participação dos alunos ocorreu de maneira mais efetiva na segunda aula. Esse movimento de reflexão realizado pelo licenciando substancia 0 argumento de Frison (2012) acerca do potencial inovador da SE nos processos de formação e, por conseguinte, sustenta as atividades desenvolvidas no decorrer da pesquisa.

\section{ANÁLISE DA ENTREVISTA FINAL (ES3)}

No semestre seguinte à proposta desenvolvida na disciplina ES2, John cursou a componente curricular ES3, a qual consistiu, principalmente, na elaboração e aplicação de atividades na escola, sob a supervisão de um professor da Educação Básica e do pesquisador/professor na universidade. A partir do conteúdo 'Cinética Química', John preparou uma sequência de quatro aulas, fundamentada 
nas ideias da SE e incorporando uma abordagem histórica dos conceitos, que foi desenvolvida com alunos do segundo ano do Ensino Médio de uma escola da rede pública estadual de ensino.

Desse modo, após todo o processo percorrido em ES3, o licenciando foi novamente entrevistado, não apenas sobre as atividades propostas no semestre corrente, mas também acerca de todo o percurso formativo vivenciado no decorrer das disciplinas ES2 e ES3, nas quais a pesquisa aqui relatada foi produzida. Devido ao grande número de questões propostas nesta etapa, a categorização das respostas de John foi realizada apenas para as questões norteadoras, as quais serviram de base para a construção de todo o diálogo.

Durante todo o processo de reflexão construído, ficou nítido o amadurecimento do licenciando ao pensar sobre a profissão docente em sua totalidade, pois, agora, John passou não apenas a mobilizar mais os saberes docentes, mas também a articulá-los ao discutir e refletir sobre as situações vivenciadas em sua formação, principalmente no decorrer dos estágios, buscando consolidar saberes e vivências que serão importantes para sua atuação no âmbito profissional, conforme veremos nas narrativas a seguir.

Na primeira questão, relatando sobre o processo criativo de planejamento e de elaboração das atividades da sequência didática, John enfatizou a organização, seguindo as etapas da SE. Embora já tivesse trabalhado com essa proposta anteriormente, pensá-la dentro de um contexto real e mais abrangente tornou-se um desafio para o licenciando.

Ao elaborar um problema para o conteúdo 'Cinética Química', atividade pertencente à primeira etapa da SE (Problematização), John comentou:

[...] antes de elaborar o problema, eu pensei em algo que despertasse a atenção dos alunos (P-1) e se encaixasse na situação de estudo (P-2). [... então eu procurei primeiro um experimento relacionado com o dia a dia para depois propor o problema (P-4). [...] o problema partiu de uma pergunta indagando os alunos sobre, na opinião deles, 0 que causava 0 escurecimento da maçã (P-7).

Em sua fala, ele demonstrou preocupação em atender às orientações para a elaboração do problema. Ao afirmar que deveria despertar a atenção do aluno e ainda fazer sentido dentro de um contexto maior na SE, o licenciando corroborou a ideia de que a problematização precisa contemplar aspectos da realidade do estudante, tornando-se um espaço para que esses expressem o seu entendimento sobre o tema a ser estudado (CRUZ; GEHLEN, 2016; MALDANER et al., 2001). Apesar disso, demonstrou ter enfrentado algumas dificuldades em sua construção, como podemos evidenciar nos fragmentos a seguir:

[...] o que mais me dificultou foi a elaboração do problema (P-11). Às vezes na hora de pensar no problema você tem que pensar em várias coisas, como que ele vai relacionar com o tema (P-12), se a partir dele eu consigo partir para outros conteúdos relacionados com esse problema... (C-1) [...] a maior dificuldade é a maneira de organizar tudo isso dentro da aula (C-3).

Assim como na segunda aula, no estágio ES2, ficou evidente que John passou a considerar o planejamento como uma prática relevante da profissão e, mesmo manifestando contrariedades, destacou como esse contato com a sala de aula na Educação Básica no papel de professor (mesmo sendo sua primeira experiência no magistério) possibilitou que ele refletisse e começasse a enxergar 
essa correlação existente, especificamente, entre o problema e 0 desenvolvimento da aula, evidenciando novas variáveis inerentes aos saberes do professor.

Percebe-se, portanto, que o trabalho com essa dinâmica possibilitou que John pensasse sobre o quê, como e por que ensinar determinado conteúdo, uma vez que ao construir sua SE existia uma demanda maior de saberes a serem mobilizados, a fim de contemplar todas as orientações trazidas pelos referenciais teóricos, como a condução das atividades dentro do planejamento com vistas a atingir os objetivos traçados inicialmente pelo professor.

Nota-se, a partir da análise dos trechos anteriores, como nesse momento da entrevista o licenciando passou a considerar outros pontos expressivos, pois, além de destacar a importância do problema e da sua relação com o cotidiano do aluno, mostrou-se consciente da necessidade de articulação entre os saberes, pois, mais do que apenas listar elementos que pudessem auxiliar 0 professor em seu trabalho de sala de aula, John fez reflexões que avançaram no sentido da integração entre os campos disciplinar, curricular e o pedagógico, ou seja, passou a considerar que muito mais do que aplicar algumas técnicas dentro de uma abordagem predominantemente "conteudista", é também papel do professor ponderar sobre as relações possíveis de serem estabelecidas entre a teoria (os conteúdos) e a prática em sala de aula, visando à aprendizagem do aluno.

Dando sequência à exposição dos relatos pertinentes às questões, o foco agora diz respeito à execução da proposta, ou seja, era preciso que John detalhasse o seu movimento de tirar o planejamento do papel e de colocá-lo em prática, em sua primeira experiência enquanto estagiário/professor na Educação Básica. Diante dessa questão sua fala inicial foi: "[...] o planejamento saiu totalmente diferente do que foi feito na prática (C-5)", e continuou:

[...] tem vários fatores que fogem daquilo que é planejado (C-6), desde a participação dos alunos (C-7), a maneira com que eles executam a atividade proposta... (C-8) às vezes tem a conversa, a atenção do aluno... (C-9) então essas coisas acabam atrapalhando no planejamento, né? (C-10). Talvez tem algum ou outro conteúdo que 0 aluno demore mais um pouco para aprender e aí você... (C-11) [...] Às vezes você planeja pra passar aquele material uma vez e na sala de aula é diferente (C-12).

Nesse trecho de seu depoimento, John mostrou que as questões alusivas à gestão de sala de aula passaram, cada vez mais, a integrar os saberes dos professores, em contradição com suas ideias iniciais, expostas e discutidas nos tópicos anteriores. Sendo assim, apresentou um movimento inicial a partir do qual pareceu perceber como a prática do professor era composta pelos mais variados e imprevisíveis fatores, que, de uma maneira ou de outra, acabavam interferindo no desenho inicial proposto para as atividades. Todavia, afirmou que, mesmo diante de um sistema complexo, 0 professor deveria guiar suas ações a partir das necessidades do aluno, promovendo um espaço que possibilitasse seu protagonismo dentro do processo de ensino e de aprendizagem.

É importante destacar aqui que, diferentemente das etapas anteriores da pesquisa, o licenciando estava, neste momento, inserido em um ambiente novo, repleto de novas relações e interações - a escola. Assim, concordamos com Frison (2012) quando afirma que o exercício profissional docente exige uma diversidade de saberes, entretanto "é na hora do ensino, ou seja, em atividade pedagógica concreta, que alguns saberes se tornam mais necessários que outros, dependendo de uma série de variáveis" (FRISON, 2012, p. 209). 
Em um movimento de reflexão, no qual John deveria avaliar o desenvolvimento da sequência didática, considerando a participação dos alunos e o tempo disponível para trabalhar os conteúdos no estágio, afirmou que as aulas foram propostas: "[...] pensando no aluno participando" (P-48) e, nessa lógica, justificou que por trazer para a aula elementos do cotidiano do aluno, contemplando as etapas da SE e a abordagem histórica, o trabalho tornou-se mais gratificante, pois não priorizou apenas a abordagem teórica: "[...] eu creio que nessas cinco aulas às vezes um professor normal daria muito mais conteúdo em duas aulas (C-14), eu trabalhei de maneira calma, conforme foram surgindo as dúvidas eu tentei responder... seguindo 0 aluno (P-51)".

Assim, segundo John, o objetivo das aulas foi pensado para que os alunos entendessem o que estavam estudando, pois "[...] às vezes passando somente teoria, passa rapidamente e 0 aluno nem lembra o que viu no final do ano e não fica uma coisa concreta, algo que o aluno entenda (D-11)" e, nesse contexto, 0 licenciando buscou romper com um modelo de ensino que propõe a ênfase nos conteúdos, priorizando, para além do conceito, o entendimento dentro de um determinado contexto.

Dando continuidade à entrevista, resgatamos alguns pontos discutidos na entrevista inicial, os quais foram bastante enfatizados pelo licenciando, buscando evidenciar como 0 processo de reflexão orientada nos estágios contribuiu para que o licenciando reforçasse ou repensasse tópicos importantes relacionados tanto à formação do professor quanto ao planejamento e à ação docente em sala de aula.

Com relação ao contato do professor com o contexto escolar, John continuou afirmando sobre a necessidade de essa relação estabelecer-se de forma mais recorrente na formação inicial, preparando 0 futuro professor para a realidade de sua profissão, uma vez que essa aproximação pode suprir algumas lacunas deixadas ao longo do processo formativo:

[...] uma coisa que você falou àquela hora do professor tentar 'linkar' a resposta do aluno ( $\mathrm{P}-52)$, às vezes essa experiência, esse contato com a sala de aula que falta, né? (E-8). As vezes tendo uma formação mais presente na sala de aula 0 aluno saia mais preparado, com mais experiência, né? (E-9).

Também durante a entrevista inicial, John comentou sobre os professores não possuírem uma cultura de planejamento das aulas e atribuiu esse fato, principalmente, à falta de tempo e à necessidade de darem conta dos conteúdos programáticos da disciplina, o que, segundo ele, impossibilitaria o professor de utilizar os saberes construídos a partir da formação. Ao ser questionado sobre esses aspectos ao final do percurso investigativo, John apresentou outro ponto de vista, por meio do qual repensou suas considerações primeiras.

0 licenciando afirmou que o tempo não deve ser um fator limitante ao trabalho do professor, pois o que deve guiá-lo é um processo reflexivo sobre a abordagem adotada e, essencialmente, sobre a aprendizagem do aluno. "Às vezes a história da ciência, por exemplo, gasta um pouco mais de tempo, mas às vezes 0 aluno entende melhor aquele conteúdo, né?" (P-58). E, diante dessa perspectiva, finalizou suas argumentações: "[...] planejar a aula, por mais que dê trabalho, tem um resultado positivo (C-16)".

Encerrando a entrevista, John foi questionado a respeito de sua evolução ao longo dos estágios. Para tal interpelação ele respondeu de maneira positiva, destacando o quanto os referenciais teóricos estudados durante a formação possibilitaram que ele repensasse, como e quais elementos seriam considerados em seu planejamento. Conforme já relatado em outros momentos, em ES2 John 
elaborou sua primeira aula sem a orientação do pesquisador/professor, pois essa etapa tinha como objetivo evidenciar quais ideias o licenciando traria para a aula, a partir de suas concepções iniciais. Sobre essa situação, o licenciando comentou:

[...] a gente tinha que propor uma aula da nossa maneira, sem nenhuma fundamentação, sem nenhuma questão, sem a utilização de nada (P-56) [...] eu vi que a gente planejou de uma maneira que não tinha identidade, não tinha uma ordem cronológica, não tinha sentido (P-57).

Ao observarmos esse relato e retomando a análise da entrevista pós ES2, vemos que o licenciando fez essas considerações, pois, segundo seus comentários, a forma como ele conduzia as atividades e as organizava dentro do tempo disponível, além de priorizar a abordagem teórica, não dava oportunidade para que os alunos participassem da construção de sua própria aprendizagem. Sendo assim, "[...] a partir do momento que a gente ganhou ferramentas como a utilização da situação de estudo e da história da ciência no ensino a nossa aula fez mais sentido... (P-54) a gente conseguia planejar o que a gente queria em cada etapa (C-15)" e, mediante essas considerações, concluiu: "[...] dessa maneira, utilizando essas ferramentas que a gente aprendeu no estágio dois, utilizando no estágio três (P-55) a gente tem uma maneira mais organizada de pensar nossa aula, algo que faça sentido (C-16)".

Diante desse ambiente constituído nos estágios, concordamos com Ataide e Silva (2011, p. 174) "que é vivenciando as práticas e as novas metodologias no seu dia a dia que o futuro professor poderá passar por uma avaliação mais elaborada do desenvolvimento de sua prática, evitando assim posturas acríticas comumente repetidas em sala de aula". Essas posturas foram assumidas nas práticas iniciais pelo licenciando.

\section{CONSIDERAÇÕES FINAIS}

0 presente artigo apresentou os resultados da análise da formação inicial de um licenciando em Química, a partir de processos de reflexão orientada nos estágios, integrando ações de ensino e de pesquisa em um espaço de diálogos e de troca de experiências entre licenciandos e professor formador. A problemática em questão faz-se pertinente tendo em vista as pesquisas na área de Ensino de Ciências voltadas para a melhoria dos processos formativos, que enfatizam sobre a importância em considerar os saberes docentes como referencial balizador na formação de professores para a Educação Básica.

A partir da análise dos relatos apresentados durante a entrevista inicial, percebemos que 0 futuro professor valorizou elementos importantes ao pensar os planejamentos didáticos, como a relevância das pesquisas educacionais e como seus resultados poderiam auxiliar o professor em sua prática diária, ressaltando também o papel dos saberes experienciais em seu desenvolvimento profissional. Porém, não refletiu sobre os saberes disciplinares e curriculares, demonstrando deficiências relacionadas ao processo formativo quando pensamos na mobilização dos saberes docentes e na articulação entre eles.

Com relação às atividades desenvolvidas na disciplina ES2, foi possível constatar como as concepções advindas da formação anterior são dificilmente abaladas, pois, mesmo que durante a entrevista inicial o licenciando tenha exteriorizado ideias que condiziam com um modelo de ensino pautado nas orientações dos referenciais teóricos, seu primeiro movimento de elaboração e desenvolvimento das aulas demonstrou a grande influência dos modelos tradicionais - vivenciados ao 
longo da formação - nas práticas e nas ações desenvolvidas a fim de solucionar problemas inerentes à profissão, ainda que em um ambiente simulado.

Durante 0 segundo bloco de aulas, ainda durante $0 \mathrm{ES} 2$, ao ser desafiado a utilizar referenciais teórico-metodológicos a fim de orientar as práticas, os modelos iniciais do licenciando foram colocados à prova, pois, ao se dar conta de que o conteúdo por si só não seria suficiente e que a articulação entre saberes disciplinares e pedagógicos não se dá de maneira simples, passou a compreender e vivenciar a complexidade da futura profissão, atribuindo mais relevância ao conjunto de saberes provenientes da formação profissional.

Os espaços constituídos na disciplina de ES3 permitiram ao licenciando reelaborar e construir novos saberes relativos ao conhecimento dos professores por meio de práticas desenvolvidas nas escolas, possibilitando perceber que, dadas as situações, alguns saberes tornaram-se mais necessários do que outros. Ao entrar em contato com esse ambiente, no papel de professor em formação, e fundamentado não somente nos referenciais teóricos estudados e orientados a utilizar, mas também mediante a experiência construída de maneira reflexiva nos momentos anteriores, o licenciando tornou-se mais crítico frente aos problemas encontrados no campo de estágio, problematizando questões importantes relativas aos processos de ensino e de aprendizagem.

Com relação às limitações da pesquisa, entendemos que as discussões associadas aos saberes curriculares extrapolam as situações do interior da sala de aula, uma vez que a estrutura curricular e os documentos que norteiam a seleção de conteúdos e os objetivos de ensino, dentre outras demandas, são pensados e organizados, muitas vezes, por agentes externos aos muros da escola. Desse modo, em nossa pesquisa, como apresentamos ao longo do texto, esses saberes encontram-se, de maneira geral, nas reflexões do licenciando sobre aspectos do planejamento, sem uma relação muito explícita com problemas mais amplos do currículo, evidenciando, assim como os referenciais teóricos apontam, uma lacuna importante no processo formativo do licenciando em Química.

De todo modo, mesmo que esse seja, ainda, um movimento muito pontual, diante da complexidade dos saberes docentes, é importante observar o potencial que as atividades desenvolvidas ao longo do processo de pesquisa tiveram no sentido de confrontar as preconcepções do futuro professor em relação à aprendizagem e ao trabalho docente.

Sendo assim, os resultados aqui apresentados sugerem a necessidade de que as propostas formativas do curso de Licenciatura em foco sejam repensadas a fim de que todas as especificidades atreladas ao exercício da docência sejam problematizadas, possibilitando um contato maior e de mais qualidade dos licenciandos tanto com as discussões propiciadas pelas pesquisas como também com 0 ambiente escolar, incluindo aqui os professores de profissão, entendendo, portanto, a necessidade de políticas específicas voltadas à promoção de modificações significativas nos estágios curriculares obrigatórios dos cursos de formação de professores de Química, dado que esse, ainda, configura-se como um dos poucos espaços voltados à prática docente ao longo da formação.

\section{REFERÊNCIAS}

AIRES, J. A.; TOBALDINI, B. G. Os saberes docentes na formação de professores de Química Participantes do PIBID. Química Nova na Escola, v. 35, n. 4, p. 272-282, 2013.

ALMEIDA, P. C. A.; BIAJONE, J. Saberes docentes e formação inicial de professores: implicações e desafios para as propostas de formação. Educação e Pesquisa, v. 33, n. 2, p. 281-295, 2007. 
ATAIDE, M. C. E. S.; SILVA, B. V. C. As metodologias de ensino de Ciências: contribuições da experimentação e da história e filosofia da ciência. Holos, v. 4, p. 171-181, 2011.

BARDIN, L. Análise de Conteúdo. São Paulo: Edições 70, 2011.

BORGES, C.; TARDIF, M. Apresentação. Educação \& Sociedade. Dossiê: os saberes dos docentes e sua formação. Cedes, n. 74, p. 11-26, 2001.

CARVALHO, A. M. P.; GIL-PÉREZ, D. Formação de professores de ciências: tendências e inovações. 10. ed. São Paulo: Cortez, 2011.

CRUZ, A. B.; GEHLEN, S. T. A mecânica do corpo humano: uma SE elaborada na formação inicial de professores de Física da Uesc. In: MASSENA, E. P. (Org.). Situação de Estudo - Processos de significação pela pesquisa em grupos interinstitucionais. ljuí: Unijuí, p. 85-109, 2016.

FONSECA, C. V.; SANTOS, F. M. T. Educação em Química, formação e trabalho docente: revisão de pesquisas brasileiras (2002-2015). Investigações em Ensino de Ciências, v. 21, n. 02, p. 179-199, 2016.

FRISON, M. D. A produção de saberes docentes articulada à formação inicial de professores de Química: implicações teórico-práticas na escola de nível médio. 2012. 310f. Tese (Doutorado) - Programa de Pós-Graduação em Educação em Ciências: Química da Vida e da Saúde da Universidade Federal do Rio Grande do Sul. Porto Alegre. 2012.

GAUTHIER, C.; MARTINEAU, S.; DESBIENS, J. F.; SIMARD, D. Por uma teoria da Pedagogia - Pesquisas contemporâneas sobre o saber docente. ljuí: Unijuí, 2013.

IMBERNÓN. F. Formação docente e profissional: formar-se para a mudança e a incerteza. 9. ed. São Paulo: Cortez, 2011.

KOLLAS, F.; MARQUES, R.; MEGIER, A. P. A.; FRISON, M. D. Saberes necessários ao bom professor: dizeres de licenciandos e estudantes da Educação Básica. Educação, v. 38, n. 3, p. 645-658, 2013.

LÜDKE, M.; ANDRÉ, M. E. D. A. A Pesquisa em educação: abordagens qualitativas. 2. ed. Rio de Janeiro: E.P.U., 2013.

MALDANER, 0. A. A formação inicial e continuada de professores de química: formando professores/pesquisadores. 3. ed. ljuí: Unijuí, 2006.

MALDANER, O. A.; ZANON, L. B.; AUTH, M.; NONENMACHER, S. E. B.; BAZZAN, A. B.; PASCOAL, S. G. Situação de Estudo como possibilidade concreta de ações coletivas interdisciplinares no Ensino Médio - Ar Atmosférico. In: III Encontro Nacional de Pesquisa em Educação em Ciências, 2001, Atibaia. Anais... Atibaia/SP, 2001.

MASSENA, E. P. (Org.). Situação de Estudo - Processos de significação pela pesquisa em grupos interinstitucionais. ljuí: Unijuí, 2016.

MELO, M. T. L. Programas oficiais para formação dos professores da Educação Básica. Educação \& Sociedade, n. 68, p. 45-60, 1999.

MORAES, R. Análise de Conteúdo. Educação, Porto Alegre, ano XXII, n. 37, p. 7-31, 1999. 
NUNES, C. M. F. Saberes docentes e formação de professores: um breve panorama da pesquisa brasileira. Educação \& Sociedade, v. 22, n. 74, p. 27-42, 2001.

SILVA, R. M. G.; SCHNETZLER, R. P. Estágios curriculares supervisionados de ensino: partilhando experiências formativas. EntreVer, v. 1, p. 116-136, 2011.

STANZANI, E. L. Saberes Docentes e a Prática nos Estágios: possibilidades na formação do futuro professor de Química. 2018. 251f. Tese (Doutorado em Educação para a Ciência) - Programa de Pós Graduação em Educação para a Ciência, Faculdade de Ciências, Universidade Estadual 'Júlio de Mesquita Filho', Bauru, 2018.

STANZANI, E. L.; GUARNIERI, P. V.; CARVALHO, W.; OBARA, C. E. Situação de Estudo e Ensino de Química: contribuições para a Educação Científica. In: XVIII Encontro Nacional de Ensino de Química, 2016, Florianópolis. Anais... Florianópolis: UFSC, 2016.

TARDIF, M. Saberes docentes e formação profissional. Rio de Janeiro: Vozes, 2014.

TARDIF, M.; LESSARD, C.; LAHAYE, L. Os professores face ao saber: esboço de uma problemática do saber docente. Teoria \& Educação, v. 1, n. 4, p. 215-233, 1991.

RECEBIDO EM: 12 ago. 2019.

CONCLUÍDO EM: 10 abr. 2020. 
